\title{
Anti-nociceptive and anti-inflammatory effects of an aqueous extract of blended leaves of Ocimum gratissimum and Psidium guajava
}

\author{
Akinyinka O. Alabi ${ }^{1,2}$, Abayomi M. Ajayi ${ }^{2^{*}}$ (D, Osarume Omorogbe ${ }^{2}$ and Solomon Umukoro ${ }^{2}$
}

\begin{abstract}
Background: To investigate the antinociceptive and anti-inflammatory activities of aqueous extract of a blended mixture of dried leaves of Ocimum gratissimum and Psidium guajava, a traditional analgesic drug polyherbal (TADP) used as a remedy for pain-related conditions.

Methods: Antinociceptive activity of TADP (100, 200 and $400 \mathrm{mg} / \mathrm{kg})$ was evaluated in the hot plate test and acetic acid-induced nociception in mice while the anti-inflammatory was evaluated in carrageenan-induced paw oedema in rats. Levels of nitrite, myeloperoxidase, glutathione and malondialdehyde were assayed in carrageenan-induced paw tissue.

Results: TADP (200 and $400 \mathrm{mg} / \mathrm{kg}$ ) significantly prolong the latency time in the hot-plate test. TADP (100-400 mg/ $\mathrm{kg}$ ) produced a dose-dependent significant inhibition of the acetic-acid induced abdominal constriction. The antinociceptive activity of TADP in the presence of naloxone and atropine was not reversed whereas yohimbine and glibenclamide significantly reversed it. TADP $(100,200$ and $400 \mathrm{mg} / \mathrm{kg})$ significantly reduced the swelling in the carrageenan-induced oedema model and also produced a reduction in the nitrite and myeloperoxidase level. TADP (400 mg/kg) significantly reduced malondialdehyde concentration and increase glutathione level in the carrageenan-induced rat paw. TADP significantly decrease the number of cellular infiltrates in the histopathological assessment.

Conclusion: These results indicate that polyherbal product containing blended leaves of Ocimum gratissimum and Psidium guajava possess antinociceptive and anti-inflammatory properties, hence represents a promising alternative remedy in inflammation-induced pain.
\end{abstract}

Keywords: Analgesic, Polyherbal, Ocimum gratissimum, Psidium guajava

\section{Introduction}

Pain is an unpleasant experience associated with actual or potential tissue damage [1] and it is also known to be sensory and therefore it is experienced emotionally. It is unarguably one of the serious problems globally and as such has lost its defensive mechanisms [2]. The intensity, duration and nature especially of chronic pain is

\footnotetext{
* Correspondence: yomexj@yahoo.com

${ }^{2}$ Department of Pharmacology and Therapeutics, Faculty of Basic Medical Sciences, College of Medicine, University of Ibadan, Ibadan, Oyo State, Nigeria

Full list of author information is available at the end of the article
}

incomparable to the extent of tissue damage that occurs [2]. It has been estimated to affect 1 in 5 adults in a population, also 1 in 10 adults is diagnosed with chronic pain each year [3]. Although, pain is a protective mechanism by which the body responds to harmful stimulus, improperly managed pain can lead to decreased productivity and diminished quality of life as it has been reported to affect the psyche, behaviour, social life of the individual and also present with socio-economic burden to the society $[2,4]$. Pain associated with nociception is the feeling whereby there is the warning against the danger of damage to tissue or it shows an already 
inflicted damage as a result of illness or injury. Patients therefore presents decreased pain threshold and increased response to stimulus resulting in increased nociception $[5,6]$.

Inflammatory pain has been reported to produce mechanical allodynia and thermal hypersensitivity which results from the release of inflammatory mediators from inflammatory or adjacent tissues. Acute inflammatory pain causes much suffering and turned to be intractable as a result of poor and ineffective treatment [7]. Inflammatory pain though a common clinical symptom still lacks effective treatment as the most frequently used agents such as non-steroidal anti-inflammatory drugs and selective cyclooxygenase- 2 inhibitors are associated with adverse effects $[6,8]$. Hence, there is the need to search for alternative therapy of plant origin that could ameliorate pain resulting from inflammation.

Ocimum gratissimum belongs to the genus Осіmum belonging to the family Lamiaceae, a widely grown plant found in tropical and subtropical regions. Ocimum gratissimum belongs to the group of plants known as spices, a sub-shrub and perennial plant [9]. The plant is economically important due to their essential oils and utilization as medicine for many disorders, including pain, fever and central nervous system. O. gratissimum leaf is reported to be rich in polyphenolic compounds (rutin, caffeic acid, cirsimaritin, xanthomicrol) and essential oils (thymol, eugenol and geraniol) $[9,10]$. The antinociceptive activity has been reported of the essential oils [10] and aqueous extract [11].

Psidium guajava, is an important food crop and medicinal plant in tropical and subtropical countries that is widely used for food and in folk medicine around of world. Psidium guajava Linn. belongs to the genus Psidium belonging to the family Myrtaceae [12]. More recent ethnopharmacological studies show that $P$. guajava is used in many parts of the world for the treatment of a number of diseases, e.g. as an anti-inflammatory, for diabetes, hypertension, dental caries, wounds, pain relief and reducing fever. The leaf of $P$. guajava is used locally in Nigerian ethnomedicine to manage, control, and/or treat a plethora of human ailments, including diabetes mellitus and hypertension [12]. The leaf is rich in essential oil with main components being $\alpha$-pinene, limonene, menthol, terpenyl acetate, isopropyl alcohol, longicyclene, cardinene and curcumene. The flavonoids found in the leaves include myricetin, quercetin, luteolin and kaempferol. The essential oil from $P$. guajava leaves and its constituent, $\alpha$-pinene have been shown to produce a significant antinociceptive effect [13].

Due to the abundance of the ethnopharmacological reports of O. gratissimum and P. guajava, careful selection of blend of the two leaves was prepared and sold as polyherbal formulation for the management of pain associated conditions, hence, the need to validate the anti-nociceptive and anti-inflammatory activities of this formulation.

\section{Methods \\ Experimental animals}

Swiss mice of either sex weighing 18-25 g were obtained from laboratory animal farms around University of Ibadan. The animals were housed in polypropylene plastic cages and maintained under environmental conditions of light and humidity and were fed with pelletized feed (Vital Feeds Ltd., PLC, Jos, Nigeria) and received water ad libitum. The animals were acclimatized for 5 days in the Pharmacology laboratory at the University of Ibadan prior to carrying out the experiments. All experiments were carried out with strict compliance to The "Principle of Laboratory Animal Care" (NIH Publication No. 85-23) and ethical guidelines for investigation of experimental pain in conscious animals.

\section{Extraction of herbal mixtures}

Dried leaves of $O$. gratissimum and $P$. guajava blended together at a ratio of 2:1 and known as traditional analgesic drug polyherbal (TADP). $100 \mathrm{~g}$ of the powdered mixture was soaked in $500 \mathrm{~mL}$ of distilled water for $24 \mathrm{~h}$ as described by Awodele et al. [14]. ,The extract was separated by filtration in white muslin cloth and doubly filtered through a cotton wool fixed in a funnel. The recovered extract was concentrated to dryness in an oven for 4 days at $50{ }^{\circ} \mathrm{C}$, giving a dark brownish color with a yield of $10.17 \%$. The extract denoted as TADP was stored in a refrigerator and daily prepared in distilled water for pharmacological assays.

\section{Evaluation of antinociceptive activity of TADP in hot plate test}

A quick and relatively inexpensive method of testing acute thermal is in using the hot plate test, it measures reaction time to lick paw or jump when mice are placed on hot surfaces [15]. In this experiment, five groups of mice $(n=6)$ each were selected. Group 1 served as control and received the vehicle (distilled water, $0.1 \mathrm{~mL} / 10 \mathrm{~g}$ b.w.). TADP at the concentration of 100, 200 and 400 $\mathrm{mg} / \mathrm{kg}$ b.w. was administered orally to groups 2,3 and 4 , respectively and group 5 received Pethidine $(5 \mathrm{mg} / \mathrm{kg}$ b.w.). The mice were placed singly in the Ugo Basile hot plate $\left(35,100\right.$, Italy) maintained at $55 \pm 1^{\circ} \mathrm{C}$ and observed for the reaction time due to the thermal stimulation. Reaction time was recorded when the animals licked their fore-and hind paws or jumped; at before (0) and $60,90,120$ and 150 min after administration of test drugs. The mice which reacted within $20 \mathrm{~s}$ were selected for the studies. 
The mean percentage maximum possible effect (\% MPE) was calculated as:

$$
\% \mathrm{MPE}=\frac{\text { Post-drug latency }- \text { Pre-drug latency }}{\text { Cut-off time-Post }- \text { drug latency }} \times 100
$$

\section{Evaluation of antinociceptive activity of TADP in acetic acid-induced nociception in mice}

Writhing was induced by intraperitoneal injection $0.6 \%$ acetic acid (0.1 mL/ 10 body weight) [16]. Five groups of mice $(n=5)$ were used in this study comprising the vehicle $(0.1 \mathrm{~mL} / 10 \mathrm{~g}$ distilled water), indomethacin $(10 \mathrm{mg} /$ $\mathrm{kg})$, or TADP $(100,200$ and $400 \mathrm{mg} / \mathrm{kg})$. Vehicle, indomethacin and TADP were administered to overnight fasted mice for $1 \mathrm{~h}$ before acetic acid (0.6\%) was administered intraperitoneally, mice were placed singly in a transparent observation box. Writhing movement was accepted as contraction of the abdominal muscles accompanied by stretching of hind limbs. The number of writhings occurring between 5 and $20 \mathrm{~min}$ were recorded. Percentage of inhibition of writhing was calculated and evaluated statistically.

\section{Evaluation of the possible mechanism of action of TADP $(400 \mathrm{mg} / \mathrm{kg})$ on acetic acid-induced writhes in mice}

To investigates the participation of the opiodergic, cholinergic, adrenergic, and nitric oxide pathway in the antinociceptive effect of the extract. Mice were pretreated with naloxone $(1 \mathrm{mg} / \mathrm{kg})$, an antagonist of opioid receptors for $15 \mathrm{~min}$ before they received TADP $(400 \mathrm{mg} / \mathrm{kg}$ ). Also, atropine $(2 \mathrm{mg} / \mathrm{kg})$, a muscarinic receptor antagonist, yohimbine $(2 \mathrm{mg} / \mathrm{kg})$, an $\alpha_{2}$ adrenergic receptor antagonist, glibenclamide $(10 \mathrm{mg} / \mathrm{kg})$, a blocker of ATPsensitive $\mathrm{K}^{+}$-channels, and L-NAME $(10 \mathrm{mg} / \mathrm{kg})$, a nonspecific inhibitor of nitric oxide synthase enzyme. The animals received acetic acid ( $0.6 \%$ i.p.) $1 \mathrm{~h}$ later, the writhing response was recorded as described above.

\section{Assessment of effect of TADP on locomotory activity in Open-field test}

To assess the possible nonspecific muscle relaxants or the sedative effects of TADP, the motor performance of the mice was evaluated on the open-field apparatus [17]. Groups of mice $(n=5)$ were treated with vehicle $(0.1$ $\mathrm{mL} / 10$ g, p.o.), TADP $(400 \mathrm{mg} / \mathrm{kg}$, p.o.) $1 \mathrm{~h}$ before the performance of the test. The mice were placed in the center of the UgoBasile activity cage apparatus and allowed to have free ambulation for 5 min of observation of the locomotion frequency (horizontal activity and vertical activity). The numbers of horizontal or vertical beams breaks were counted automatically by the activity meter.
Evaluation of anti-inflammatory properties of TADP in carrageenan-induced paw oedema model

Inflammatory oedema was induced in the right hind paw of female rats according to the method described by Winter et al. [18]. ,The animals were divided into five groups $(n=5)$; group 1 was negative control group that was orally pre-treated with vehicle $(10 \mathrm{~mL} / \mathrm{kg}$ distilled water), groups $2-4$ were orally pre-treated with TADP $(100,200$ and $400 \mathrm{mg} / \mathrm{kg})$ and group 5 received indomethacin $(10 \mathrm{mg} / \mathrm{kg})$. One hour after oral pre-treatment, $0.1 \mathrm{ml}$ of $1 \%$ carrageenan was injected into the right hind paw of each rat under the subplantar aponeurosis. Measurement of paw volumes was done before and at $1,2,3$, and $4 \mathrm{~h}$ after injection of carrageenan using the UgoBasile (7134) digital plethysmometer. The increase in paw volume was calculated and plotted against time (hour). The area under the curve for the increase against time was computed from 0 to $4 \mathrm{~h}$. The percentage of inhibition of total oedema formation was calculated with the formula below

$$
\begin{aligned}
\% \text { inhibition }= & {[(\text { AUC of control-AUC of treatment }) /} \\
& \text { AUC of control }] \times 100 \%
\end{aligned}
$$

\section{Collection and homogenization of inflamed paws}

The animals were euthanised by deep ether anaesthesia, paw were removed just below the ankle joints, cleaned in sodium phosphate buffer and weighed. The wet paws were weighed and recorded. The paws were frozen at $-20^{\circ} \mathrm{C}$. The frozen paws were homogenized in cold phosphate buffer by grinding with mortar and pestle placed in an ice bucket. The homogenized paws were centrifuged at $10,000 \mathrm{rpm}$ for $10 \mathrm{~min}$ at $4{ }^{\circ} \mathrm{C}$ in refrigerated centrifuge. Aliquot of the supernatant was used to assay for levels of nitrite, reduced glutathione, malondialdehyde (MDA) and myeloperoxidase enzyme activities in carrageenan-injected paws.

\section{Biochemical analysis}

Aliquots of supernatant were used to measure the production of nitric oxide in the carrageenan-injected paws. Nitrite level was measured using Griess reagent assay [19]. Myeloperoxidase enzyme activity as index of neutrophil activation in paw was determined according to the method of Bradley et al. [20]. ,MDA levels as a marker of lipid peroxidation was determined using the thiobarbituric acid reactive substance (TBARS) assay [21]. The method as described by Sin et al. [22], was adopted in the determination of reduced glutathione concentration in carrageenaninjected paw. 
Evaluation of the effect of TADP on the histopathological changes in carrageenan-induced rat paw

Carrageenan-injected paws were fixed in 10\% buffered formalin. For histological evaluation, the paw samples were embedded in paraffin and sectioned; 4-lm-thick sections were deparaffinized, stained with hematoxylin and eosin $(H \& E)$, and then examined under a light microscope by an experienced pathologist without knowledge of the treatments.

\section{Statistical analysis of data}

Data obtained from animal studies were expressed as mean \pm standard error of mean (SEM). Data were analysed for significant main effect using one-way analysis of variance (ANOVA) followed by Newman-Keuls post hoc multiple comparison test. Values were considered statistically significant when $p<0.05$.

\section{Results}

\section{Effect of TADP in hot plate test}

Oral treatment of TADP at $100 \mathrm{mg} / \mathrm{mL}$ did not significantly change the latency time in the hot plate test at $55^{\circ} \mathrm{C}$ compared with the vehicle-treated animals whereas TADP 200 and $400 \mathrm{mg} / \mathrm{kg}$ and Pethidine $(5 \mathrm{mg} / \mathrm{kg})$ significantly $(p<0.05)$ increased the maximal possible effect (Fig. 1a). The area under the curve for prolonged latency at $60-150 \mathrm{~min}$ is as shown in Fig. 1b below. TADP (200 and $400 \mathrm{mg} / \mathrm{kg}$ ) significantly prolonged latency by $68.6 \%$ and $69.3 \%$, respectively. Pethidine $(5 \mathrm{mg} /$ $\mathrm{kg}$ ) significantly prolonged latency by $77.7 \%$.

\section{Effect of TADP in acetic-acid induced writhing test}

As shown in Table 1 below, oral administration of TADP $(100-400 \mathrm{mg} / \mathrm{kg})$ produced a dose-dependent and significant $(p<0.05)$ inhibition of acetic-acidinduced abdominal constrictions in mice. Maximum inhibition of $54.1 \%$ was observed at TADP $400 \mathrm{mg} / \mathrm{kg}$ while indomethacin treatment produced $84.6 \%$ inhibition of writhes.

\section{Effect of TADP on locomotory performance in mice}

Treatment with TADP $400 \mathrm{mg} / \mathrm{kg}$ caused an insignificant $(p>0.05)$ increase in horizontal beam breaks representing spontaneous locomotory activity but significantly reduced the rearing activity. Pethidine did not cause a significant reduction in the number of vertical beam breaks representing rearing (Table 2 ).

\section{Possible mechanism of antinociceptive activity of TADP in acetic acid-induced writhing}

As shown in Fig. 2 below, the antinociceptive activity of TADP was not reversed by naloxone $(1 \mathrm{mg} / \mathrm{kg})$. This shows that TADP is not acting via the opioid receptors. Atropine $(2 \mathrm{mg} / \mathrm{kg})$, a muscarinic receptor antagonist did not reverse the antinociceptive activity of TADP (400 $\mathrm{mg} / \mathrm{kg})$, howbeit insignificantly $(p>0.05)$ enhanced the activity in the acetic acid-induced writhing test. Yohimbine $(2 \mathrm{mg} / \mathrm{kg})$, an $\alpha_{2}$-adrenoceptor antagonist significantly reversed the anti-nociceptive activity of TADP $(400 \mathrm{mg} / \mathrm{kg})$ in the acetic acid-induced writhing test (Fig. 2). Glibenclamide $(10 \mathrm{mg} / \mathrm{kg})$, given $15 \mathrm{~min}$ prior to TADP $(400 \mathrm{mg} / \mathrm{kg})$ significantly $(p<0.05)$ reversed the antinociceptive activity of TADP when assessed in the acetic acid-induced writhing test. L-NAME $(10 \mathrm{mg} / \mathrm{kg})$, an inhibitor of nitric oxide synthase did not modify the antinociceptive activity of TADP $(400 \mathrm{mg} / \mathrm{kg})$ in the acetic acid-induced writhing test.
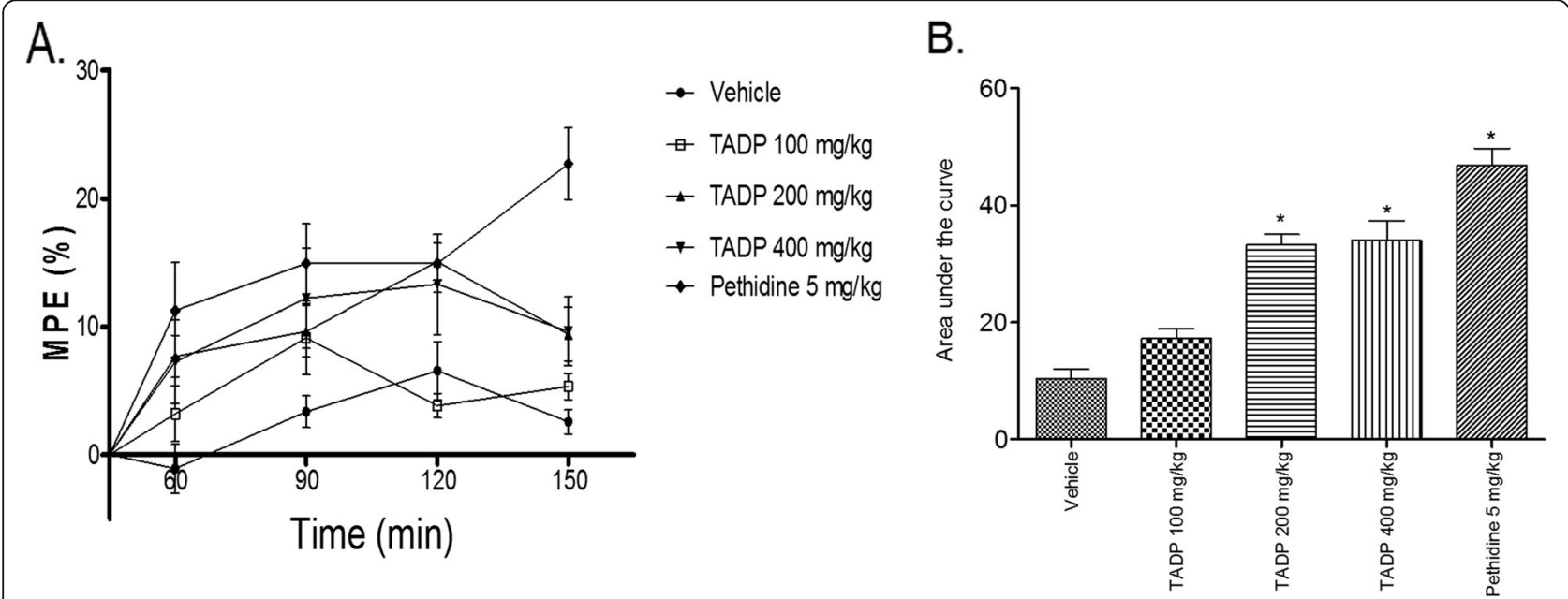

Fig. 1 Antinociceptive effect of TADP in hot plate a Percent maximal possible effect, $\mathbf{b}$ Area under the curve for percent maximal effect. Data represents Mean \pm SEM of five mice, ${ }^{*} p<0.05$ denotes significant difference compared to vehicle group only (1-way ANOVA followed by Newman-Keuls Multiple comparison post hoc test) 
Table 1 Effect of TADP on acetic acid-induced writhing in mice

\begin{tabular}{llll}
\hline Treatment & Dose $(\mathrm{mg} / \mathrm{kg})$ & N_of writhings $^{\circ}$ & $\begin{array}{l}\text { Inhibition of } \\
\text { writhing (\%) }\end{array}$ \\
\hline Vehicle & $10 \mathrm{~mL} / \mathrm{kg}$ & $53.2 \pm 2.3$ & - \\
TADP & 100 & $42.2 \pm 3.6$ & $20.7^{*}$ \\
TADP & 200 & $40.0 \pm 3.8$ & $24.8^{*}$ \\
TADP & 400 & $24.4 \pm 4.4$ & $54.1^{*}$ \\
Indomethacin & 10 & $8.2 \pm 0.7$ & $84.6^{*}$ \\
\hline
\end{tabular}

Data represents Mean \pm SEM of five mice

*denotes significant value at $p<0.05$

\section{Effect of TADP on carrageenan-induced rat paw oedema} Induction of acute inflammation in vehicle (distilled water) rats resulted in a prominent increase in paw volume beginning at $1 \mathrm{~h}$ post carrageenan injection and reached a peak at $4 \mathrm{~h}$ (Fig. 3a). The degree of swelling of the carrageenan-injected paw was significantly $(p<0.05)$ reduced in animals that were pretreated with TADP (100, 200 and $400 \mathrm{mg} / \mathrm{kg})$ and indomethacin $(10 \mathrm{mg} / \mathrm{kg})$. As shown in Fig. 3b, pretreatment with TADP extract $(100,200$ and $400 \mathrm{mg} / \mathrm{kg})$ significantly decrease $(p<0.05)$ the paw inflammatory response measured as area under the curve (AUC) by 35.1\%, 52.7\% and 57.9\%, respectively. Indomethacin $(10 \mathrm{mg} / \mathrm{kg})$ significantly reduced the total inflammatory response by $75.7 \%$ (Fig. 3b).

\section{Effect of TADP on nitrite level in carrageenan-induced rat paw}

As shown in Fig. 4a, injection of carrageenan into the rat hind paw induced a marked increase in the nitrite level $4 \mathrm{~h}$ after injection. The treatment of rats with TADP (100, 200 and $400 \mathrm{mg} / \mathrm{kg}$ ) and indomethacin $(10 \mathrm{mg} / \mathrm{kg})$ caused a significant decreased of the carrageenan-induced increased NO in the paw tissue. Four hours after injection of carrageenan in rat paws, there was an increase in MPO activity as a marker of neutrophil infiltration in paw tissue of vehicle treated rats (Fig. 4b). This effect was significant $(p<0.05)$ at TADP $(100,200$ and $400 \mathrm{mg} / \mathrm{kg})$ by $49.7 \%$, $42.8 \%$ and $31.1 \%$, respectively. Indomethacin also showed a significant $(p<0.05)$ reduction of paw MPO activity.

Table 2 Effect of TADP on Locomotory activity in mice in the open field test

\begin{tabular}{llll}
\hline Treatment & Dose & $\begin{array}{l}\text { Spontaneous locomotor } \\
\text { activity (horizontal beam } \\
\text { breaks/5 min) }\end{array}$ & $\begin{array}{l}\text { Rearing (vertical } \\
\text { beam breaks/ 5 min) }\end{array}$ \\
\hline Vehicle & $10 \mathrm{~mL} / \mathrm{kg}$ & $398.3 \pm 16.3$ & $21.2 \pm 1.7$ \\
TADP & $400 \mathrm{mg} / \mathrm{kg}$ & $413.0 \pm 10.4$ & $8.00 \pm 4.0^{*}$ \\
Pethidine & $5 \mathrm{mg} / \mathrm{kg}$ & $618.5 \pm 27.4^{*}$ & $16.0 \pm 2.3$ \\
\hline
\end{tabular}

Data represents Mean \pm SEM of five mice

*denotes significant value at $p<0.05$

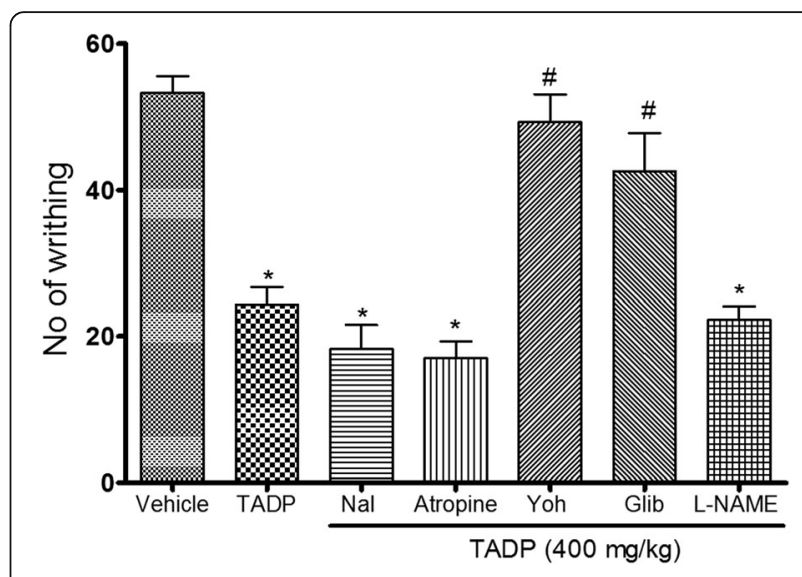

Fig. 2 Antinociceptive activity of TADP in the presence of different blockers in the acetic acid-induced writhing in mice. Each bar represents the mean of five mice \pm SEM. ${ }^{*} p<0.05$ compared to vehicle, \# $p<0.05$ compared to TADP as determined by 1-way ANOVA followed by Newman Keuls post hoc multiple comparison test

Effect of TADP on carrageenan-induced oxidative stress in rat paw

The protective role of TADP on carrageenan-induced oxidative stress in rat paw was assessed by measuring lipid peroxidation and reduced glutathione level. As shown in Table 3 , TADP $(400 \mathrm{mg} / \mathrm{kg})$ and indomethacin $(10 \mathrm{mg} / \mathrm{kg})$ significantly $(p<0.05)$ reduced the malondialdehyde level when compared to vehicle treated animals. Carrageenan-induced a depletion of GSH levels in control rats (Table 3 ), which was prevented by TADP $(400 \mathrm{mg} / \mathrm{kg})$ and indomethacin $(10 \mathrm{mg} / \mathrm{kg})$.

\section{Effect of TADP on Histopathological examination of carrageenan-induced paw tissue oedema}

As shown in Fig. 5, paw tissue of vehicle-treated rats showed an acute inflammation with extensive extravasations, there are widespread dense amounts of mononuclear inflammatory cells just below the epidermis and extending throughout the dermis to the hypodermis. Blood vessels are markedly congested (Fig. 5). As observed in Fig. 5, treatment of rats with TADP at $100,200,400 \mathrm{mg} / \mathrm{kg}$ and indomethacin $(10 \mathrm{mg} / \mathrm{kg})$ exhibited a significant decrease in the number of cellular infiltrates.

\section{Discussion}

This study was carried out to establish the antinociceptive and anti-inflammatory effects produced by the oral administration of an aqueous extract of polyherbal formulation of blended leaves of Ocimum gratissimum and Psidium guajava in rodents. The results show that TADP at higher doses showed pronounced anti-noceptive activity as it was able to significantly prolong the latency time in the hot-plate test and also produce a significant inhibition 


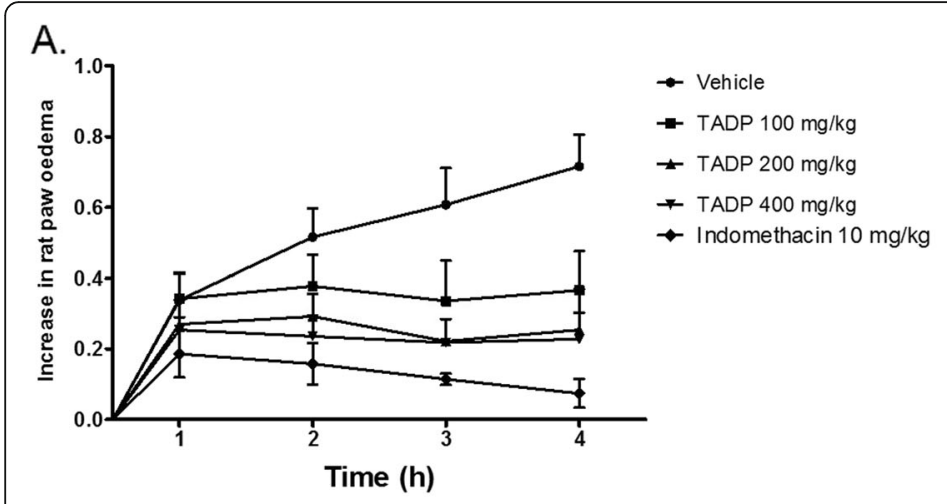

B.

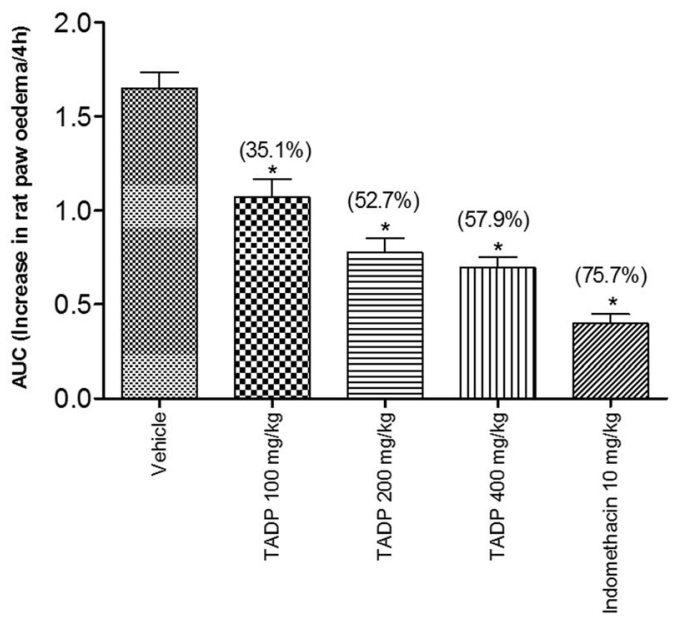

Fig. 3 Anti-inflammatory effect of TADP on carrageenan-induced rat paw oedema. a Change in paw volume, $\mathbf{b}$ Total oedema responses measured as area under the curve (AUC). Each column represents Mean \pm SEM of five rats. Values in parenthesis are percentage inhibition of paw inflammation. Significant effect denoted by ${ }^{*} p<0.05$ compared to vehicle by one-way ANOVA followed by Newman Keuls post hoc multiple comparison test

in the acetic-acid induced abdominal constriction. TADP at a dose of $400 \mathrm{mg} / \mathrm{kg}$ increase the horizontal beam break and a reduction in the rearing behaviour. TADP significantly reduced the swelling in the carageenan-induced oedema model and produced a reduction in the nitrite and myeloperoxidase level. TADP at a dose of $400 \mathrm{mg} / \mathrm{kg}$ significantly reduced malondialdehyde concentration and increased glutathione level in the caragenaan-induced increased oxidative stress level. TADP and indomethacin significantly decrease the number of cellular infiltrates in the histopathological assessment.

Thermally -induced nociception in the hot plate is considered to be selective for centrally acting analgesic compounds (morphine-like drugs). TADP showed positive activity in this test. On the other hand, the acetic acid-induced abdominal-writhing test is considered as a conventional animal model of pain and one of the most sensitive methods used for the screening of substances
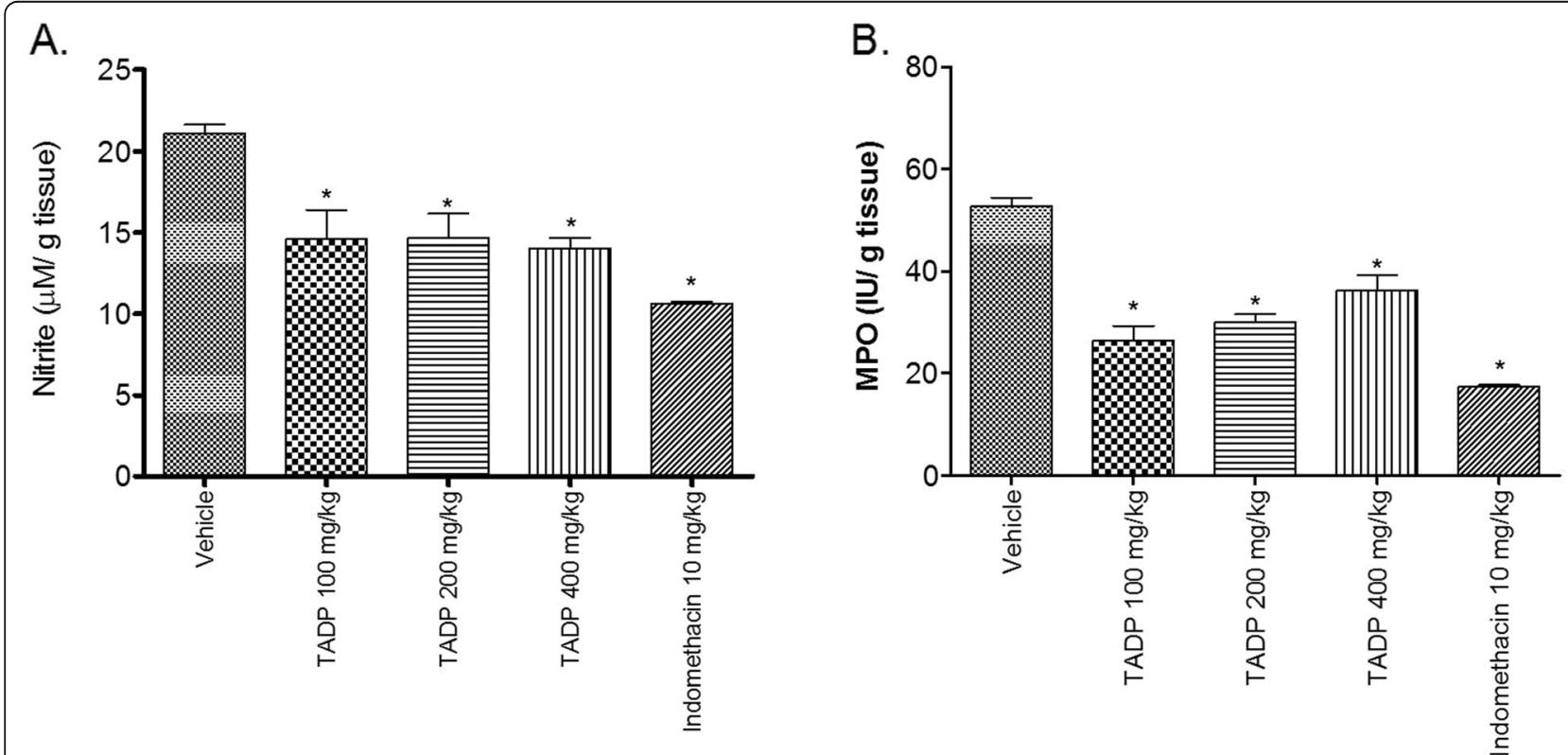

Fig. 4 Effect of TADP on a nitrite, $\mathbf{b}$ myeloperoxidase, in carrageenan-induced rat paw. Data represents Mean + SEM of five rats. Significant effect denoted by ${ }^{*} p<0.05$ compared to vehicle by one-way ANOVA followed by Newman Keuls post hoc multiple comparison test 
Table 3 Antioxidant effect of TADP in carrageenan-induced rats paw

\begin{tabular}{llll}
\hline Treatment & Dose $(\mathrm{mg} / \mathrm{kg})$ & $\begin{array}{l}\text { TBARs }(\eta M \text { MDA } \\
\mathrm{g} \text { tissue })\end{array}$ & GSH $(\mu \mathrm{M} / \mathrm{g}$ tissue $)$ \\
\hline Vehicle & $10 \mathrm{~mL} / \mathrm{kg}$ & $2.84 \pm 0.13$ & $2.40 \pm 0.25$ \\
TADP & 100 & $2.50 \pm 0.19$ & $2.96 \pm 0.26$ \\
TADP & 200 & $2.48 \pm 0.11$ & $2.57 \pm 0.24$ \\
TADP & 400 & $2.18 \pm 0.13^{*}$ & $3.04 \pm 0.21^{*}$ \\
Indomethacin & 10 & $1.89 \pm 0.08^{*}$ & $3.24 \pm 0.23^{*}$ \\
\hline
\end{tabular}

Data represents Mean \pm SEM of five mice

*denotes significant value at $p<0.05$

that have both analgesic origin and/or anti-inflammatory effects [23]. Injection of acetic acid into the peritoneal cavity induces nociception by directly activating nonselective cationic channels located in the primary afferent pathways or indirectly by promoting the release of various endogenous algesic mediators such as prostaglandins, cytokines, bradykinin and others, as well as increasing lipoxygenase (LOX) and cyclooxygenase (COX) production in peripheral tissues [24]. The release of these endogenous substances with subsequent stimulation and sensitization of the peripheral primary afferent $\mathrm{C}$-fibers neurons in the animal peritoneum produced a viscerosomatic reflex leading to abdominal constrictions [24].

The findings of the present study indicate that the oral pre-treatment of mice with aqueous extract of polyherbal formulation of the leaves of $O$. gratissimum and P. guajava produced a significant dose-dependent reduction in the number of abdominal writhing induced by acetic acid as compared to the control group. This finding suggests that the antinociceptive action of TADP in the acetic acidinduced abdominal-writhing test could be the result of inhibited release of endogenous algesic mediators or direct inhibitory activity at nerve endings of the primary afferent neurons and/or inhibition of the transmission pathway entering the dorsal horn.

The experimental models of nociception in mice are very good and sensitive models but however they are non-specific because, in the writhing test for instance, the response can be suppressed by muscle relaxants and other types of drugs, which could lead to misinterpretation of the results. In order to rule out the chances of false positive effect of TADP, we evaluated its effect on spontaneous locomotor function in the activity meter cage. TADP did not alter the exploratory activity but significantly reduced rearing activities. The results revealed that the observed anti-nociceptive effect of TADP was not as a result of sedation but slight impairment of rearing activity in mice.

The acetic acid-induced test was used in the investigation of the possible mechanism of antinociceptive activity of aqueous extract of polyherbal formulation of $O$. gratissimum and P. guajava leaves. Acetic acid-induced writhing represent a predictive model because it provokes a stereotyped behavior in mice. Transmission of visceral nociceptive pathway is related to the spinal cord, paravertebral nucleus and certain hypothalamic nuclei is
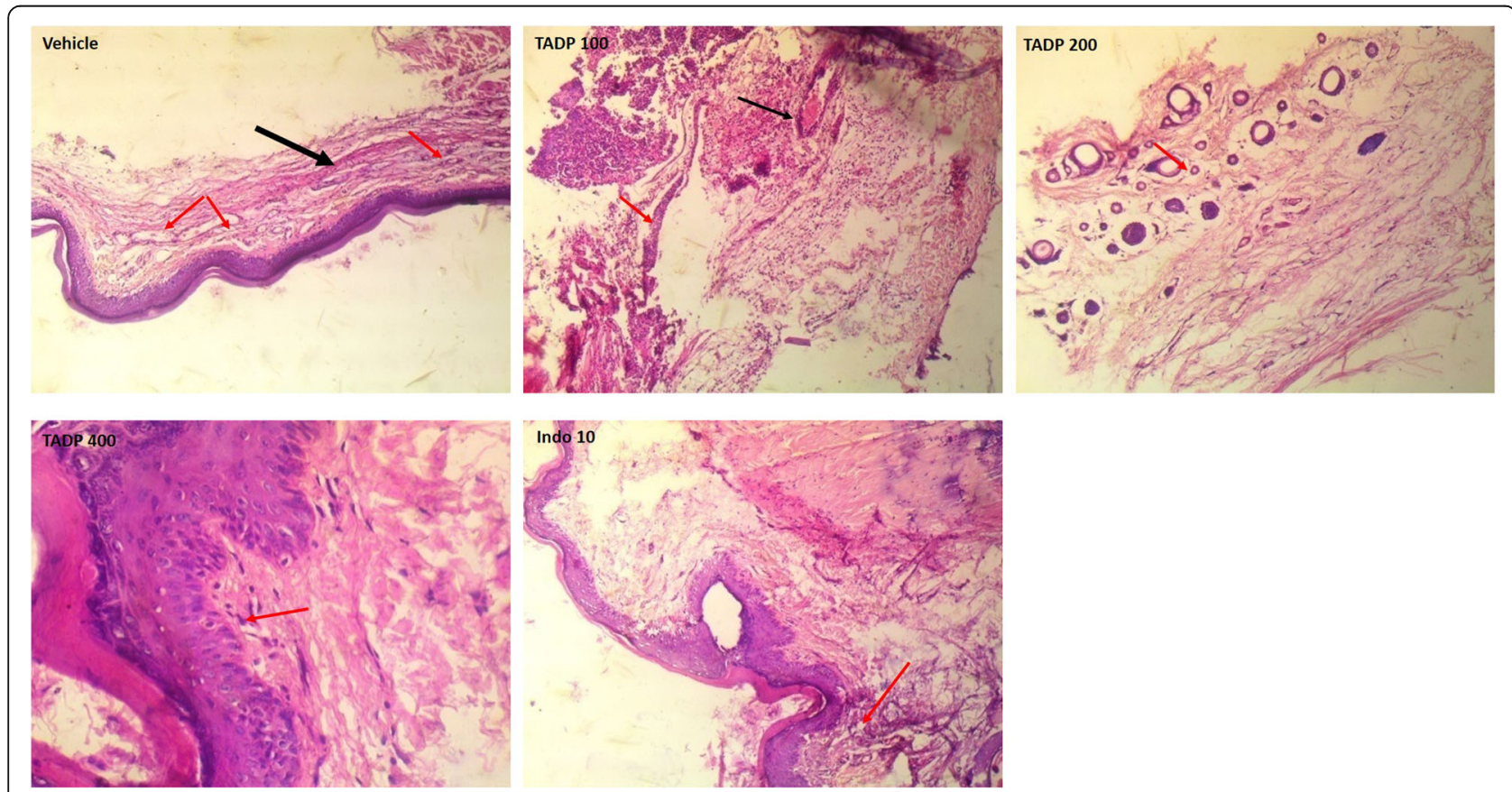

Fig. 5 Photomicrograph of histopathologic examination of paw tissue of rats treated with TADP, $5 \mathrm{~h}$ after injection of carrageenan (Carr). Sections were stained with $\mathrm{H}$ and $\mathrm{E}, \times 400$. Red color arrow indicates polymorphonuclear cell infiltration, black arrow indicates vascular congestion 
well defined in this model [25]. Thus, it is possible to investigate the possible anti-nociceptive activity of TADP in this model.

The results showed that pretreatment with naloxone, atropine and L-NAME did not significantly reversed the antinociceptive activity of TADP in the acetic acidinduced writhing test. This suggests that TADP does not activate the opioid receptors or increases the endogenous opioid system. Also, it seems that there was no interaction with the cholinergic muscarinic receptor system or the nitric oxide synthase enzymes. Interestingly, the antinociceptive activity of TADP was significantly reversed by yohimbine, an $\alpha_{2}$-adrenoceptor antagonist. An interaction between dopaminergic, adrenergic and opioid systems has been suggested in the modulation of pain perception [26]. The reversal of the antinociceptive effect of the extract by yohimbine further confirms the interaction between the dopaminergic, adrenergic and opioid system because the systems play a vital role in regulating pain perception. The dopaminergic system has been reported as a potential target for the treatment of chronic pain because dopaminergic agonists were recently shown to promote recovery of locomotor function following an injury to the spinal cord [27]. However, the adrenergic and the dopaminergic system has shown the effects of the nociceptive responses through the modulation of presynaptic inhibition in mouse [28]. Antinociceptive effect of some flavonoids such as quercetin has been shown to involve the participation of the alpha-2 adrenergic systems in the modulation of pain [29]. Thus, analgesics drugs act through the descending circuits [30]. Furthermore, our result showed that the antinociceptive effect of TADP is related to the ATP-sensitive $\mathrm{K}^{+}$-channels. Pretreatment with glibenclamide, a blocker of the ATP-sensitive $\mathrm{K}^{+}$-channels decreased the antinociceptive effect of TADP.

Inflammatory reactions cause high filtration of neutrophils into the tissue and thereby increase the level of myeloperoxidase. The activity of Myeloperoxidase has been used as a good model to estimate neutrophil content in inflamed tissues and therefore it has been widely used as a biomarker of inflammation [20,31]. MPO secretion by stimulated neutrophils acts as a host defense mechanism by mediating microbial killing. MPO is secreted in large quantity during inflammation because it is highly effective during inflammatory processes and also for its use as an indicator of polymorphonuclear leukocytes presence in tissues, MPO has been widely used as an inflammatory marker of both acute and chronic conditions [31, 32]. Moreover, MPO changes have also been associated to the severity of many pain related diseases [33-35]. Injection of Carrageenan increases the myeloperoxidase content in the paw which was reduced by the blended extract of $\mathrm{O}$. gratissimum and P. guajava.
Increased oxidative stress has been reported to be associated with increased pain. Reactive oxygen species (ROS) is known to play an important role in the pathogenesis of so many disease states resulting in pains [36] that is characterized by altered metabolic conditions of cells, increased production of ROS, thus increased oxidative stress acts as a mediator of pain stimuli. Although, the body possesses antioxidant defences and repair mechanisms against free radical oxidative stress, increase level of free radicals in the body increases its oxidative stress level thereby hindering the defence mechanism [37]. Thus, the use of plants with antioxidant property could serve as a remedy to pain. The results show that TADP at a higher dose reduces the level of malondialdehyde which was increased by the administration of carrageenan and as prevent depletion of reduced glutathione.

Carrageenan-induced inflammation depends on paw tissue nitrite production [38]. Recruitment of inflammatory cells to the site are possible source of NO during inflammation, therefore a potential target of TADP effect. Reduction in inflammatory cells recruitment was observed from the histopathological examination of the paw tissue from the H\&E staining. This reduction might account for the reduced level of nitrite determined in the paw tissues.

\section{Conclusion}

In conclusion, this study provides evidence that aqueous extract of polyherbal blend of leaves of Ocimum gratissimum and Psidium guajava possesses good antinociceptive and anti-inflammatory activities in rodents. It further suggests that the antinociceptive mechanisms might partly involve interaction with adrenergic pathways, while antiinflammatory effects might be due to inhibition of oxidative stress.

\section{Abbreviations \\ AUC: Area under the Curve; GSH: Reduced glutathione; H\&E: Hematoxylin and Eosin; MPO: Myeloperoxidase; TADP: Traditional Analgesic Drug Polyherbal; TBARS: Thiobarbituric Acid Reacting Substances}

\section{Acknowledgements \\ The authors are grateful to the Department of Pharmacology and Therapeutics, University of Ibadan for providing the facilities.}

\section{Authors' contributions \\ AAO, AMA and SU conceived and designed the experiments. AAO and AMA performed the experiments; AMA analysed the data;AAO, AMA and $O O$ wrote the paper. All authors read and approved the final manuscript. \\ Funding \\ Not applicable \\ Availability of data and materials \\ The datasets supporting the conclusions in the article are included within the article.}

Ethics approval and consent to participate

Authors declared that all experiments were carried out with strict compliance to The "Principle of Laboratory Animal Care" (NIH Publication No. 
85-23) and ethical guidelines for investigation of experimental pain in conscious animals.

\section{Consent for publication}

Not applicable

\section{Competing interests}

The authors declare that they have no competing interests.

\section{Author details}

${ }^{1}$ Department of Pharmacology and Therapeutics, Olabisi Onabanjo University, Ago-iwoye, Ogun State, Nigeria. ${ }^{2}$ Department of Pharmacology and Therapeutics, Faculty of Basic Medical Sciences, College of Medicine, University of Ibadan, Ibadan, Oyo State, Nigeria.

Received: 16 February 2019 Accepted: 10 October 2019

Published online: 04 November 2019

\section{References}

1. Olaleye SB, Ige AO, Michael OS, Owoyele BV. Analgesic and antiinflammatory effects of ethanol extracts of Buchholzia coriacea seeds in male rats. Afr J Biomed Res. 2012:15:171-6.

2. Vaskova J, Kocan L, Vasko L. Oxidative stress and opioids. Global J Anes. 2016. https://doi.org/10.17352/2455-3476.000027.

3. Goldberg DS, McGee SJ. Pain as a global health priority. BMC Public Health. 2011;11:770

4. Swieboda P, Filip RS, Prystupa A, Drozd M. Assessment of pain: types, mechanism and treatment. Ann Agric Environ Med. 2013;1:2-7.

5. Kiguchi N, Maeda T, Kobayashi Y, et al. Involvement of inflammatory mediators in neuropathic pain caused by vincristine. Int Rev Neurobiol. 2009:85:179.

6. Sun S, Yin Y, Yin X, Cao F, Luo D, Zhang T, Li Y, Ni L. Anti-nociceptive effects of Tanshinone IIA (TIIA) in a rat model of complete Freund's adjuvant (CFA)induced inflammatory pain. Brain Res Bull. 2012;88:581.

7. Okuda K, Takeshima N, Hagiwara S, Takatani J, Uchino T, Noguchi T. New anthranilic acid derivative, EAntS-GS, attenuates Freund's complete adjuvant-induced acute pain in rats. J Surg Res. 2012:175:265.

8. Tadros NN, Bland L, Legg E, Olyaei A, Conlin MJ. A single dose of a nonsteroidal anti-inflammatory drug (NSAID) prevents severe pain after ureteric stent removal: a prospective, randomised, double-blind, placebocontrolled trial. BJU Int. 2013;111:101-5.

9. Ajayi AM, Tanayen JK, Ezeonwumelu JOC, Dare S, Okwanachi A, Adzu B, Ademowo OG. Anti-inflammatory, anti-nociceptive and total polyphenolic content of hydroethanolic extract of Ocimum gratissimum L. leaves. Afr J Med Sci. 2014;43:215-24

10. Rabelo M, Souza EP, Soares PMG, Miranda AV, Matos FJA, Criddle DN Antinociceptive properties of the essential oil of Ocimum gratissimum L. (Labiatae) in mice. Brazil J Med Biol Res. 2003:36:521-4.

11. Tanko Y, Magaji GM, Yerima M, Magaji RA, Mohammed A. Antinociceptive and anti-inflammatory activities of aqueous extract of Ocimum gratissimum (labiate) in rodents. Afr J Trad CAM. 2008;5:141-6.

12. Gutierrez RMP, Mitchell S, Solis SV. Psidum guajava: a review of its traditional uses, phytochemistry and pharmacology. J Ethnopharmacol. 2008;117:1-27.

13. Santos FA, Rao VSN, Silveira ER. Investigations on the antinociceptive effect of Psidium guajava leaf essential oil and its major constituents. Phytother Res. 1998;12:24-7.

14. Awodele O, Oreagba IA, Odoma S, Silva JA, Osunkalu VO. Toxicological evaluation of the aqueous leaf extract of Moringa oleifera lam. (Moringaceae). J. Ethnopharmacol. 2012;139:330-6.

15. Hunskaar S, Hole K. The formalin test in mice: Dissociation between inflammatory and non-inflammatory pain. Pain. 1987;30:103-14.

16. Koster R, Anderson M, de Beer EJ. Acetic acid for analgesic screening. Fed Proc. 1959:18:412.

17. Archer J. Tests for emotionality in rats and mice. A review. Animal Behav. 1973;21:205-35.

18. Winter CA, Risley EA, Nuss CW. Carrageenan - induced oedema in the hind paw of the rat as an assay for anti - inflammatory drugs. Proc Soc Exp Biol Med. 1962;111:544-7.

19. Green LC, Wagner DA, Glogowski J, Skipper PL, Wishnok JS, Tannenbaum SR. Analysis of nitrate, nitrite, and [15N] nitrate in biological fluids. Anal Biochem. 1982;126:131-8.
20. Bradley PP, Priebat DA, Christensen RD, Rothstein G. Measurement of cutaneous inflammation: estimation of neutrophil content with an enzyme marker. J Investigative Dermatol. 1982;78:206-9.

21. Nagababu E, Rifkind JM, Sesikeran B, Lakshmaiah N. Assessment of Antioxidant Activities of Eugenol by in vitro and in vivo Methods. Methods in Mol Biol (Clifton, N.J.). 2010;610:165-80.

22. Sin YM, Pook SH, Tan TM, Petterssoon A, Kara AU, Teh WF. Changes in Gluthathione and its associated enzymes during carrageenan-induced acute inflammation in mice. Comp Biochem Physiol. 1997;116C:191-5.

23. Le Bars D, Gozariu M, Cadden SW. Animal models of nociception. Pharmacol Rev. 2001:53:597-652.

24. Ikeda Y, Ueno A, Naraba H, Oh-ishi S. Involvement of vanilloid receptor VR1 and prostanoids in theacid-induced writhing responses of mice. Life Sci. 2001;69:2911-9.

25. Cervero F, Laird JM. Visceral pain. Lance. 1999;353:2145-8.

26. Pollard H, Llorens C, Schwartz JC. Localization of opiate receptors and enkephalin in the rat striatum in relationship with the nigrostriatal dopaminergic system: lesion studies. Brain Res. 1978;151:392-8.

27. Sharples SA, Kohlinger K, Humpreys JM. A parallel pathways for the modulation of spinal locomotor networks. Front Neural Circuits. 2014:8:55.

28. Garcia-Ramirez DL, Calvo JR, Hochman S. Serotonin, Dopamine and Noradrenaline adjust actions of myelinated afferents via modulation of presynaptic inhibition in the mouse spinal cord. PLoS One. 2014;9:e89999 doi: 10/1371/journal.pone.00899999.ecollection 2014

29. Naidu PS, Singh A, Kulkarni SK. D2-dopamine receptor and a2adrenoreceptor mediated analgesic response of quercetin. Ind J Exp Biol. 2003:41:1400-4

30. Finnerup NB, Attal N. Pharmacotherapy of neuropathic pain: time to rewrite the rulebook? Pain management. 2015;14:162-73.

31. Faith $M$, Sukumaran A, Pulimood AB, Jacob M. How reliable an indicator of inflammation is myeloperoxidase activity? Clin Chim Acta. 2008;396:23-5.

32. Queiroz-Junior CM, Pacheco CM, Fonseca AH, Caliari AK, Francischi JN. Myeloperoxidase content is a marker of systemic inflammation in a chronic condition: the example given by the periodontal disease in rats. Mediators inflammation. 2009;760837. https://doi.org/10.1155/2009/760837.

33. Hampton MB, Kettle AJ, Winterbourn CC. Inside the neutrophil phagosome: oxidants, myeloperoxidase, and bacterial killing. Blood. 1998;92:3007-17.

34. Smith QT, Hinrichs JE, Melnyk RS. Gingival cervicular fluid myeloperoxidase at periodontitis sites. J Periodontal Res. 1986;21:45-55.

35. Schierwagen C, Bylund-Fellenius AC, Lundberg C. Improved method for quantification of tissue PMN accumulation measured by myeloperoxidase activity. J Pharmacol Methods. 1990;23:179-86.

36. Vašková J, Kočan L, Vaško L, Firment J. Restoration of antioxidant enzymes in the therapeutic use of selenium in septic patients. Wien KlinWochenschr. 2013;125:316-25.

37. Lobo V, Patil A, Phatak A, Chandra N. Free radicals, antioxidants and functional foods: impact on human health. Pharmacogn Rev. 2010;4:118-26.

38. Posadas I, Bucci M, Roviezzo F, Rossi A, Parente L, Sautebin L, Cirino G. Carrageenan-induced mouse paw oedema is biphasic, age-weight dependent and displays differential nitric oxide cyclooxygenase-2 expression. Br J Pharmacol. 2004;142:331-8.

\section{Publisher's Note}

Springer Nature remains neutral with regard to jurisdictional claims in published maps and institutional affiliations. 